University of South Carolina

Scholar Commons

\title{
An Infrared Imaging Method for High-Throughput Combinatorial Investigation of Hydrogenation-Dehydrogenation and New Phase Formation of Thin Films
}

H. Oguchi

Jason R. Hattrick-Simpers

University of South Carolina - Columbia, simpers@cec.sc.edu

I. Takeuchi

E. J. Heilweil

L. A. Bendersky

Follow this and additional works at: https://scholarcommons.sc.edu/eche_facpub

Part of the Optics Commons, and the Other Chemical Engineering Commons

Publication Info

Published in Review of Scientific Instruments, Volume 80, Issue 7, 2009, pages \#073707-.

(C) Review of Scientific Instruments 2009, AIP (American Institute of Physics).

Oguchi, H., Hattrick-Simpers, J., Takeuchi, I., Geilweil, E. J., \& Bendersky, L. A. (July 2009). An Infrared Imaging Method for High-Throughput Combinatorial Investigation of Hydrogenation-Dehydrogenation and New Phase Formation of Thin Films. Review of Scientific Instruments, 80 (7), \#073707. http://dx.doi.org/ $10.1063 / 1.3184024$

This Article is brought to you by the Chemical Engineering, Department of at Scholar Commons. It has been accepted for inclusion in Faculty Publications by an authorized administrator of Scholar Commons. For more information, please contact digres@mailbox.sc.edu. 


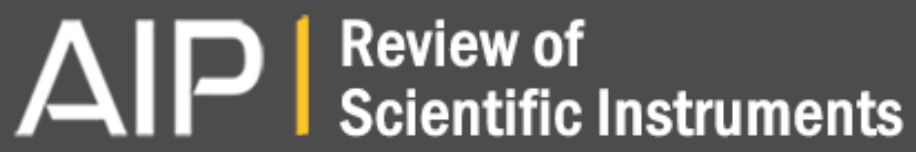

\section{An infrared imaging method for high-throughput combinatorial investigation of hydrogenation-dehydrogenation and new phase formation of thin films}

H. Oguchi, J. Hattrick-Simpers, I. Takeuchi, E. J. Heilweil, and L. A. Bendersky

Citation: Review of Scientific Instruments 80, 073707 (2009); doi: 10.1063/1.3184024

View online: http://dx.doi.org/10.1063/1.3184024

View Table of Contents: http://scitation.aip.org/content/aip/journal/rsi/80/7?ver=pdfcov

Published by the AIP Publishing

\section{Articles you may be interested in}

Porous $\mathrm{Mg}$ formation upon dehydrogenation of $\mathrm{MgH} 2$ thin films

J. Appl. Phys. 109, 093501 (2011); 10.1063/1.3574664

Crystal coherence length effects on the infrared optical response of $\mathrm{MgO}$ thin films Appl. Phys. Lett. 97, 191913 (2010); 10.1063/1.3515901

The TiAl channel mechanism for enhanced (de)hydrogenation kinetics in Mg-based films

Appl. Phys. Lett. 97, 111905 (2010); 10.1063/1.3489672

Positron depth profiling of the structural and electronic structure transformations of hydrogenated Mg-based thin films

J. Appl. Phys. 105, 043514 (2009); 10.1063/1.3075762

High-throughput combinatorial study of local stress in thin film composition spreads

Rev. Sci. Instrum. 78, 072208 (2007); 10.1063/1.2755779

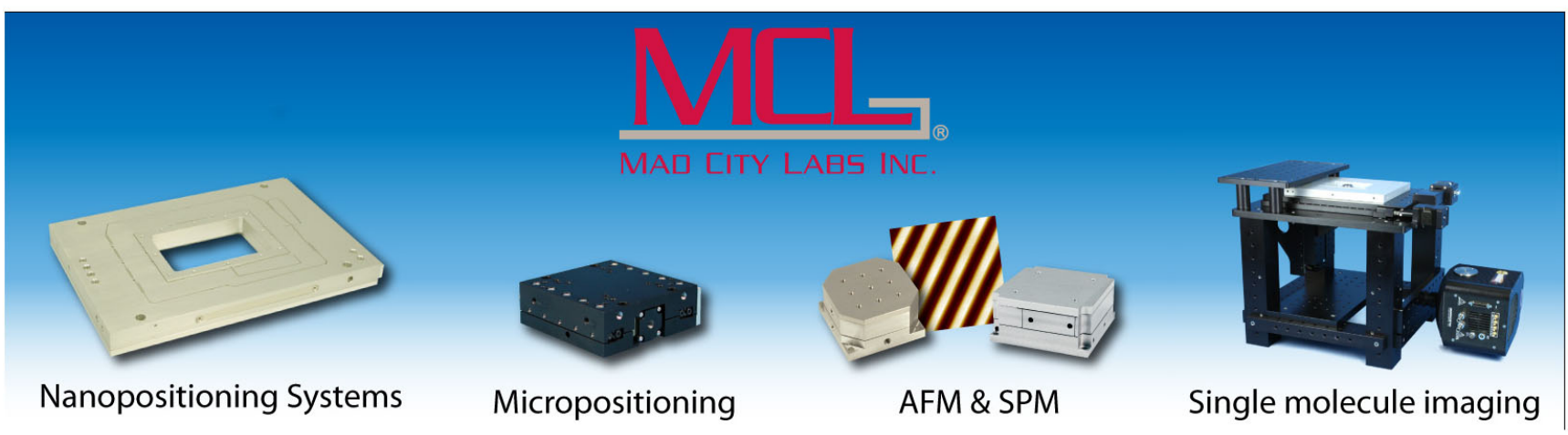




\title{
An infrared imaging method for high-throughput combinatorial investigation of hydrogenation-dehydrogenation and new phase formation of thin films
}

\author{
H. Oguchi, ${ }^{1,2,3, a)}$ J. Hattrick-Simpers, ${ }^{4}$ I. Takeuchi, ${ }^{1}$ E. J. Heilweil, ${ }^{5}$ and L. A. Bendersky ${ }^{4}$ \\ ${ }^{1}$ Department of Materials Science and Engineering, University of Maryland, College Park, \\ Maryland 20742, USA \\ ${ }^{2}$ Institute for Materials Research, Tohoku University, Sendai 980-8577, Japan \\ ${ }^{3}$ Graduate School of Engineering, Tohoku University, Sendai 980-8579, Japan \\ ${ }^{4}$ Materials Science and Engineering Laboratory, National Institute of Standards and Technology, \\ Gaithersburg, Maryland 20899, USA \\ ${ }_{5}^{5}$ Physics Laboratory, National Institute of Standards and Technology, Gaithersburg, Maryland 20899, USA
}

(Received 9 April 2009; accepted 30 June 2009; published online 30 July 2009)

\begin{abstract}
We have developed an infrared imaging setup enabling in situ infrared images to be acquired, and expanded on capabilities of an infrared imaging as a high-throughput screening technique, determination of a critical thickness of a Pd capping layer which significantly blocks infrared emission from below, enhancement of sensitivity to hydrogenation and dehydrogenation by normalizing raw infrared intensity of a $\mathrm{Mg}$ thin film to an inert reference, rapid and systematic screening of hydrogenation and dehydrogenation properties of a $\mathrm{Mg}-\mathrm{Ni}$ composition spread covered by a thickness gradient Pd capping layer, and detection of formation of a $\mathrm{Mg}_{2} \mathrm{Si}$ phase in a $\mathrm{Mg}$ thin film on a thermally oxidized Si substrate during annealing. () 2009 American Institute of
\end{abstract} Physics. [DOI: 10.1063/1.3184024]

\section{INTRODUCTION}

Due to the pressing social need for alternative sources of energy, especially for transportation applications, the search for new lightweight hydrogen storage materials has intensified. ${ }^{1,2}$ The ideal material would take on a large amount of hydrogen per weight and volume at a moderate temperature in the time it would take to fill up a conventional car's gas tank. To date, the majority of this research has been done using traditional one-by-one synthesis and measurement techniques. ${ }^{3-16}$

Although a combinatorial approach, where a large number of samples are synthesized in a single experiment, processed, and then rapidly characterized in parallel, ${ }^{17-23}$ has the potential to significantly expedite the discovery of new hydrogen storage materials, only a few groups have adopted it so far. ${ }^{24-28}$ In large part, the hesitance to this new methodology is based on the lack of an effective screening technique, frequently the bottleneck for new combinatorial studies. A few screening techniques for hydrogen storage materials have been proposed such as deflection of cantilever arrays, ${ }^{24}$ nanocalorimetry, ${ }^{25}$ and an optical imaging. ${ }^{26,27}$ In addition, infrared (IR) imaging put forward by Olk et al. ${ }^{28}$ is one of the promising screening techniques. This method can be complementary to the optical imaging as some materials are active for IR but not for visible light and vice versa due to their different properties in visible and IR spectral regions.

In thermodynamics, Kirchhoff's law of thermal radiation is a general statement equating emission and absorption in

\footnotetext{
${ }^{\text {a)} E l e c t r o n i c ~ m a i l: ~ h . o g u c h i @ i m r . t o h o k u . a c . j p . ~}$
}

heated objects, as proposed by Gustav Kirchhoff in $1859 .{ }^{29}$ Accordingly, normal spectral emissivity $\varepsilon(\lambda)$ is related to normal spectral reflectivity $R(\lambda)$ as

$$
\varepsilon(\lambda)=1-R(\lambda) .
$$

Reflectivity and emissivity in the IR are linked to electrical conductivity via the complex dielectric function. Reflectivity (for normal incidence) depends on the property of material through components of its complex refractive index $N=n+i \kappa$

$$
R=\frac{\left(n-n_{0}\right)+\kappa^{2}}{\left(n+n_{0}\right)+\kappa^{2}},
$$

where $n$ is the refractive index, $\kappa$ is the extinction coefficient, and $n_{0}$ is the refractive index of the ambient medium. From this, the relationship between emissivity and conductivity can be established. ${ }^{30-32}$

In the IR spectral region where the wavelength of the light is sufficiently long, the Hagen-Rubens relation (for normal incidence of radiation) provides a direct relationship between emissivity and electrical resistivity $\rho$ (Refs. 30 and 31)

$$
\varepsilon(\omega) \approx 2 \sqrt{2 \varepsilon_{0} \omega \rho},
$$

where $\varepsilon_{0}$ is the dielectric constant of vacuum and $\omega$ is the angular frequency of electromagnetic wave.

From these relations, it follows that metals generally have considerably lower emissivities than insulators. The absorption of hydrogen in metals and alloys results in new scattering centers and eventually leads to a modified density of states, which is often accompanied by a rise in the Fermi energy $E_{f} \cdot{ }^{33-36}$ The shift in $E_{f}$ to an energy with a lower density of states leads to a less metallic character and there- 
fore an increase in the electrical resistance or change in conductivity from metallic to insulating. Thus IR emissivity is expected to increase with the increase in hydrogen in a material.

Surface roughness of the material also affects emissivity. In the IR spectral region, reflectivity is expressed as

$$
R=R_{0} \exp \left[-(4 \pi \sigma)^{2} / \lambda^{2}\right],
$$

where $R_{0}$ is the specular reflectivity of a perfectly smooth surface and $\sigma$ is the root mean square roughness of the surface. ${ }^{37}$ However, considering microscopically smooth surface after hydrogenation, ${ }^{38}$ the effect of the surface roughness is expected to be negligible in our study.

Every material is a natural IR emitter at ordinary temperature range, thus no light source is necessary for imaging measurement. In addition, as IR imaging is sensitive to temperature change because of IR emission's proportionality to the fourth power of temperature, ${ }^{29}$ it has a capability to detect the tiny temperature change due to heat of reaction corresponding to hydrogenation and dehydrogenation.

In this paper, the samples were prepared in the form of a thin film, whose unique advantages sometimes work effectively on the investigation of the hydrogen storage materials. For example, superior control on the layer thickness and interface was applied to make multilayered thin films, which improved hydrogenation and dehydrogenation properties. ${ }^{39,40}$ Thin films also enabled sophisticated study of the hydrogen reaction on the $\mathrm{Mg}$ surface layer. ${ }^{41,42}$ In spite of these advantages, one always has to keep it in his mind that large stresses generated in thin films due to clamping to the substrate changes hydrogenation and dehydrogenation properties, and simple comparison to bulk samples becomes difficult. ${ }^{43,44}$ However, thin films still insist on their benefits in the combinatorial approach for the materials' discovery since properties dependence on systematically varied factors, such as compositions, can be compared with each other under homogeneously induced stress. ${ }^{26}$

\section{EXPERIMENTAL SETUP}

Shown in Fig. 1(a) is a top view diagram of the IR imaging setup. Hydrogenation and dehydrogenation of the samples take place inside the vacuum reaction chamber (red) with six $11.43 \mathrm{~cm}$ diameter conflat flanges (two are not used and not shown in the figure).

Working counterclockwise from the left, the first flange is connected to normal purity Ar gas (99.9\%) and ultrahigh purity $\mathrm{H}_{2}$ gas $(99.999 \%)$ for purging and hydrogenation. The gas pressure is measured by a pressure gauge. For safety, the extra pressure is released from a back-pressure regulator.

The second is used to mount a heating stage. The thin film samples are mounted on the heating stage electronically connected to a temperature controller. Figure 1(b) shows a top view diagram of the heating stage. In the figure, as an example, a Mg thin film sample deposited on a substrate and a $k$-type thermocouple are shown clamped on the heating stage by stainless steel clamps, which are screwed into the edge of the stage. The heating stage has two concentric frames of 2.79 and $3.43 \mathrm{~cm}$ diameters. A gap between the inner and outer frames increases the heating efficiency. The

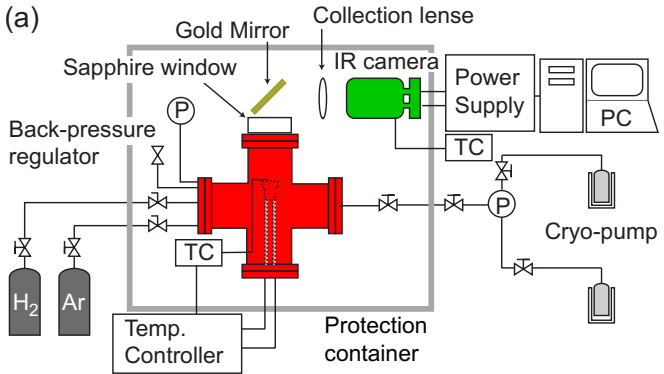

(b)

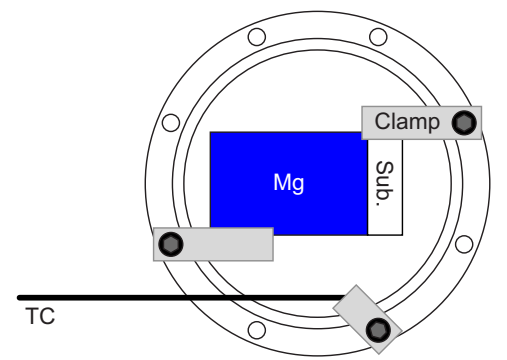

FIG. 1. (Color online) (a) A top view diagram of the IR imaging setup. The reaction chamber with the heating stage and the IR camera are in red and green, respectively. TC, $\mathrm{P}$, and $\mathrm{PC}$ denote the $k$-type thermocouple, the pressure gauge, and the personal computer, respectively. (b) A top view diagram of the heating stage.

heating stage can withstand up to $1473 \mathrm{~K}$ in vacuum and its temperature is controlled within $1 \mathrm{~K}$ accuracy.

The third connects to a vacuum system. Liquid nitrogen molecular sieve dual-stage cryopumps are used to evacuate the chamber.

The fourth offers optical imaging of the sample through a $4.45 \mathrm{~cm}$ diameter by a $0.63 \mathrm{~cm}$ thick sapphire window facing parallel to the heating stage. Rubber o-rings (not shown) on both sides of the window ensure sealing, and protect the window from point contacts to metal. During imaging measurements, IR emission between wavelength of 0.1 and $5.5 \mu \mathrm{m}$ from the thin film sample and the substrate is transmitted through the sapphire window, reflected by a gold mirror, and imaged onto the focal plane of an IR detector via a transparent $\mathrm{CaF}_{2}$ collection lens. A micrometer (not shown) attached to the base of the camera permits fine-tuning of the distance between the collection lens and the IR detector to optimize focusing of the sample image. Double-sided polished Si wafers (not shown) placed between the gold mirror and the collection lens serve as $50 \%$ attenuators to prevent saturation of the detector.

The liquid-nitrogen-cooled IR detector was used for low noise operation. The temperature of the detector is monitored by a $k$-type thermocouple directly inserted into the camera Dewar. The IR detector consists of an array of $256 \times 256$ InSb diode pixels and dual output video is internally triggered at $25 \mathrm{~Hz}$ (or slower) to permit "snap-shot" frame imaging with $10 \mathrm{~ms}$ or longer integration times. Custom-made software periodically collects the wavelength-integrated IR emission, which is amplified by multistage analog amplifiers attached to the camera. Analog data is digitally converted by dual 16-bit A/D converters and the image is processed by a digital frame-grabber (Mutek). ${ }^{45}$ The program then collects each IR image consisting of a $256 \times 256$ IR intensity data matrix. The image collection rate per time is controlled by an 
external trigger source that can vary from $40 \mathrm{~ms}$ to several minutes. Each image is then saved as a binary image file for later processing and image analysis.

The entire system is set on a $76.20 \times 67.31 \times 6.35 \mathrm{~cm}^{3}$ breadboard. For safety from potential high pressure explosion, the system is enclosed in a $76.20 \times 85.09$ $\times 101.60 \mathrm{~cm}^{3}$ protection container using high-impact, safety-rated plastic windows with two doors, which allow access to the chamber during sample loading.

\section{DEMONSTRATION}

All the thin film samples discussed in this paper were deposited in a combinatorial electron beam deposition chamber at room temperature (RT). Details of the deposition schemes for composition spread and thickness gradient thin film samples can be found elsewhere. ${ }^{46,47}$ Prior to the IR imaging, all samples were transferred in ambient atmosphere from the deposition chamber to the reaction chamber. After loading the samples, the reaction chamber was Ar purged twice and pumped down to $1 \times 10^{-6}$ bar by the cryopumps.

Throughout the IR imaging experiments, IR images were collected every $30 \mathrm{~s}$. In differential imaging mode, which was exclusively used in this study, an IR image collected at RT was used as the background; The raw IR intensity is defined as [(IR intensity at measurement temperature) -(IR intensity at RT)].

\section{A. Effect of Pd capping layer on IR imaging}

$\mathrm{Pd}$ is commonly used in hydrogen storage thin film experiments as a capping layer to prevent oxidization and to facilitate splitting of hydrogen molecules at the $\mathrm{Pd}$ surface. ${ }^{48-50}$ However, metallic Pd with small electrical resistivity $\rho$ and large reflectivity $R$ [see Eqs. (1) and (3)] is expected to block IR emission from below. Thus if one is interested in studying the hydrogenation and dehydrogenation of the materials under the Pd capping layer, one has to know how the thickness of the Pd capping layer affects the IR imaging.

To study the effect of the $\mathrm{Pd}$ capping layer on the IR imaging, we recorded the IR images of a $\mathrm{Pd}(0-50 \mathrm{~nm}) / \mathrm{C}$ (carbon) (300 nm) bilayer thickness gradient thin film sample on an $\mathrm{Al}_{2} \mathrm{O}_{3}$ (0001) substrate [Fig. 2(a)]. During measurement, the sample temperature $\left(T_{s}\right)$ was increased from 323 to $423 \mathrm{~K}$ at $5 \mathrm{~K} / \mathrm{min}$ and then kept at $423 \mathrm{~K}$ for 70 min. Carbon was chosen due to its high IR emissivity.

Figure 2(b) shows a representative top view IR image of the sample recorded at $423 \mathrm{~K}$. The position of the clamp is outlined by the dashed white line. In order to analyze the effect of the Pd capping layer on the IR imaging, the raw IR intensities extracted from the IR image are plotted as a function of the Pd thickness $\left(t_{\mathrm{Pd}}\right)$ in Fig. 2(c). Up to $t_{\mathrm{Pd}} \approx 8 \mathrm{~nm}$ the raw IR intensity increases, and then for $t_{\mathrm{Pd}}>8 \mathrm{~nm}$ it gradually decreases until around $30 \mathrm{~nm}$. The constant intensity for more than $t_{\mathrm{Pd}}=30 \mathrm{~nm}$ indicates that the IR emission from the carbon layer is completely blocked by the metallic $\mathrm{Pd}$ layer if its thickness exceeds $\approx 30 \mathrm{~nm}$. This result provided guidance for designing thin film samples in the following experiments. (a)

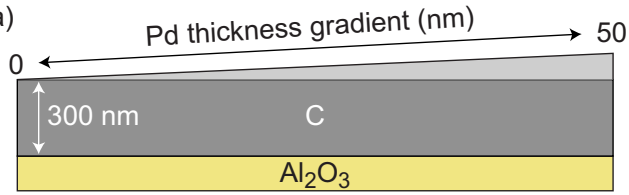

(b)
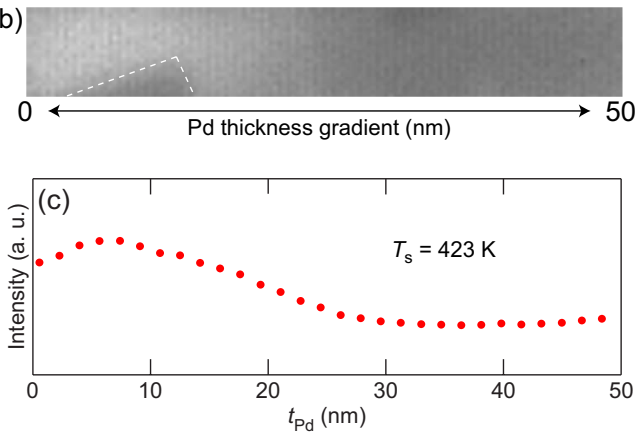

FIG. 2. (Color online) (a) A cross-sectional schematic and (b) a top view IR image of a $\mathrm{Pd} / \mathrm{C}$ bilayer thickness gradient sample at $423 \mathrm{~K}$ deposited on an $\mathrm{Al}_{2} \mathrm{O}_{3}$ (0001) substrate. (c) 29 raw IR intensities as a function of the Pd thickness $\left(t_{\mathrm{Pd}}\right)$.

\section{B. Normalization of raw IR intensity and detection of hydrogenation and dehydrogenation}

Here first importance of normalization of the raw IR intensity is demonstrated in hydrogenation of a $100 \mathrm{~nm}$ thick $\mathrm{Mg}$ thin film sample deposited on an $\mathrm{Al}_{2} \mathrm{O}_{3}$ (0001) substrate [Fig. 3(a)], and second, a capability of the IR imaging to detect hydrogenation and dehydrogenation of the thin film samples is verified.

In the hydrogenation process, $T_{S}$ was maintained at 373 $\mathrm{K}$ and hydrogen gas pressure $\left(P_{\mathrm{H}}\right)$ was rapidly increased to 1 bar from vacuum. Obtained IR intensity curves, composed of a large number of raw IR intensities plotted as a function of $t$, of the $\mathrm{Al}_{2} \mathrm{O}_{3}$ substrate (light gray), and the $\mathrm{Mg}$ thin film (dark gray), are shown together with a normalized IR intensity curve (green) [(raw IR intensity curve of $\mathrm{Mg}$ )/(raw IR intensity curve of $\left.\mathrm{Al}_{2} \mathrm{O}_{3}\right)$ ] in Fig. 3(b). $\mathrm{Mg}$ shows significant increase in intensity including a small spike immediately af-

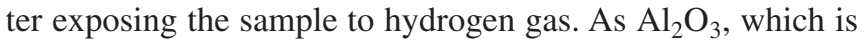
inert to hydrogen gas, also shows such a spike, it can be noise. The noise complicates and can mislead data interpretation. On the other hand, normalization smoothes out such an unfavorable feature. Thus, data interpretation becomes easier and more accurate, and the sensitivity to subtle changes in IR emissivity due to hydrogenation and dehydrogenation is remarkably enhanced. Hereafter, the normalization IR intensity curve is used instead of the raw IR intensity curve.

After hydrogenation, $T_{s}$ was first reduced to RT and the hydrogen gas was pumped out of the chamber. Then, in the dehydrogenation process, the substrate was heated back up to $423 \mathrm{~K}$ at $5 \mathrm{~K} / \mathrm{min}$ and kept constant. An intensity of an IR intensity curve [Fig. 3(c)] decreases with $T_{s}>400 \mathrm{~K}$.

Since only hydrogen gas is in and out of the chamber in the hydrogenation and dehydrogenation process, the increase and decrease in IR intensities are presumably attributed to hydrogenation and dehydrogenation of the thin film sample, respectively.

In order to empirically evidence this presumption, $\theta-2 \theta$ 

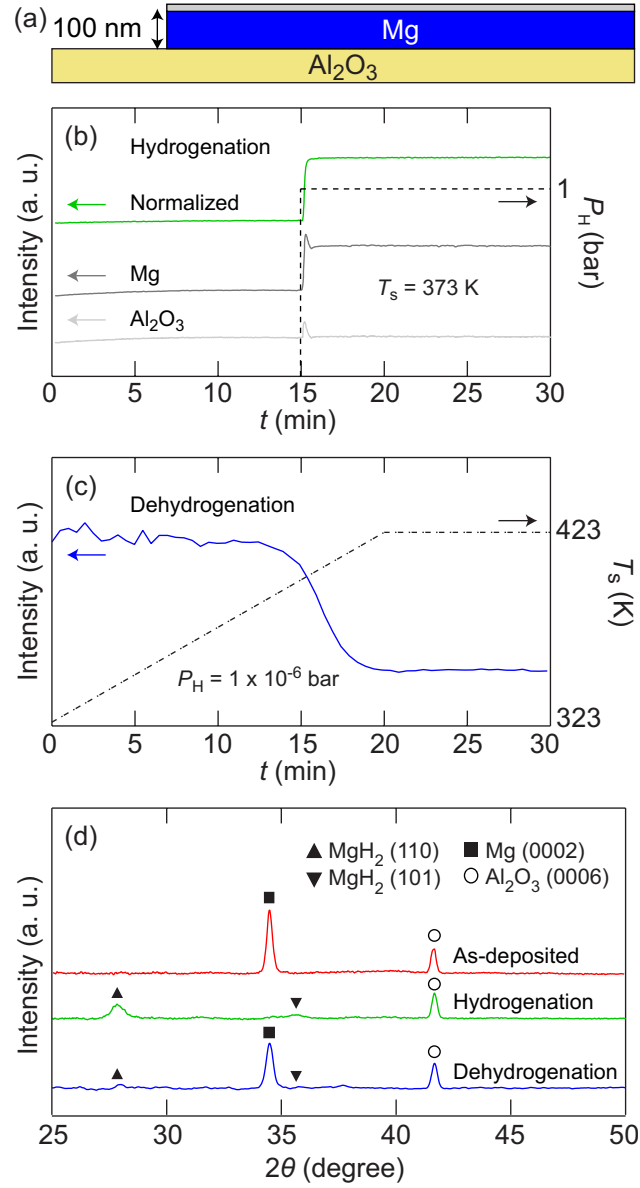

FIG. 3. (Color online) (a) A cross-sectional schematic of a $100 \mathrm{~nm}$ thick $\mathrm{Mg}$ thin film sample with a $5 \mathrm{~nm}$ thick Pd capping layer deposited on an $\mathrm{Al}_{2} \mathrm{O}_{3}$ (0001) substrate. (b) Raw IR intensity curves of the $\mathrm{Al}_{2} \mathrm{O}_{3}$ substrate (light gray) and the $\mathrm{Mg}$ thin film (dark gray), and a normalized IR intensity curve (green) obtained in the hydrogenation process. Hydrogen gas pressure $\left(P_{\mathrm{H}}\right)$ (dashed line) is added for reference (right axis). (c) A normalized IR intensity curve obtained in the dehydrogenation process (left axis) and a sample temperature for reference (chain line) (right axis). (d) $\theta-2 \theta$ XRD (Cu $K \alpha$ radiation) patterns of a $\mathrm{Mg}$ thin film sample before hydrogenation (asdeposited) (red), after hydrogenation (green), and after dehydrogenation (blue).

X-ray diffraction (XRD) was implemented. In Fig. 3(d), other than the $\mathrm{Al}_{2} \mathrm{O}_{3}$ (0006) substrate peak at $41.7^{\circ}$, only the $\mathrm{Mg}$ (0002) peak at $34.4^{\circ}$ was observed for the as-deposited sample (red). After hydrogenation process (green), the $\mathrm{Mg}$ peak almost disappeared. Instead, the $\mathrm{MgH}_{2}$ (110) and (101) peaks were observed at $27.9^{\circ}$ and $35.7^{\circ}$, respectively. After the dehydrogenation process (blue), the $\mathrm{MgH}_{2}$ peaks almost disappeared and the $\mathrm{Mg}$ peak reappeared. The reactions suggested by the $\theta-2 \theta$ XRD patterns are only the $\mathrm{MgH}_{2}$ formation and decomposition in the hydrogenation and dehydrogenation processes, respectively. This supports our presumption, e.g., the increase and decrease in IR intensities should be directly attributed to hydrogenation and dehydrogenation, respectively.

\section{Systematic investigation of hydrogenation and dehydrogenation in a $\mathrm{Mg}-\mathrm{Ni}$ composition spread}

To illustrate the capability of the IR imaging technique to screen hydrogenation and dehydrogenation properties of a (a)
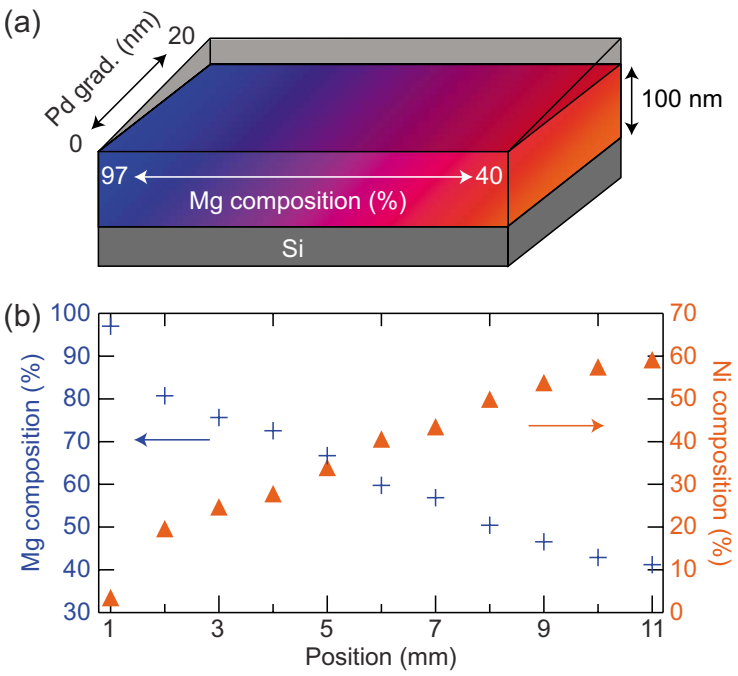

FIG. 4. (Color online) (a) Schematic of a $100 \mathrm{~nm}$ thick Mg-Ni composition spread sample deposited on a thermally oxidized $\mathrm{Si}$ (100) substrate with a thickness gradient Pd capping layer. (b) $\mathrm{Mg}-\mathrm{Ni}$ composition variation measured by EDS plotted as a function of position of the sample along the composition spread. Cross and triangle are for the $\mathrm{Mg}$ composition (left axis) and for the Ni composition (right axis), respectively.

sample with locally varied parameters, a $\mathrm{Mg}-\mathrm{Ni}$ composition spread was monitored while cycling hydrogen in and out of the chamber. Figure 4(a) shows the geometry of the $\mathrm{Mg}-\mathrm{Ni}$ composition spread. In a horizontal direction, a $100 \mathrm{~nm}$ thick continuous $\mathrm{Mg}-\mathrm{Ni}$ composition spread was grown. The composition variation was measured by energy dispersive spectroscopy (EDS) as shown in Fig. 4(b). In the orthogonal direction, a Pd thickness gradient from 0 to $20 \mathrm{~nm}$ was grown as a capping layer. This unique sample geometry allows for the simultaneous study of the effect of $\mathrm{Mg}-\mathrm{Ni}$ composition and thickness of the Pd capping layer on hydrogenation and dehydrogenation properties.

Figures 5(a)-5(e) show representative top view IR images of the $\mathrm{Mg}-\mathrm{Ni}$ composition spread. Under 1 bar hydrogen gas pressure at $t=1.5 \mathrm{~h}$ [Fig. $5(\mathrm{~b})]$, the $\mathrm{Mg}$ rich side

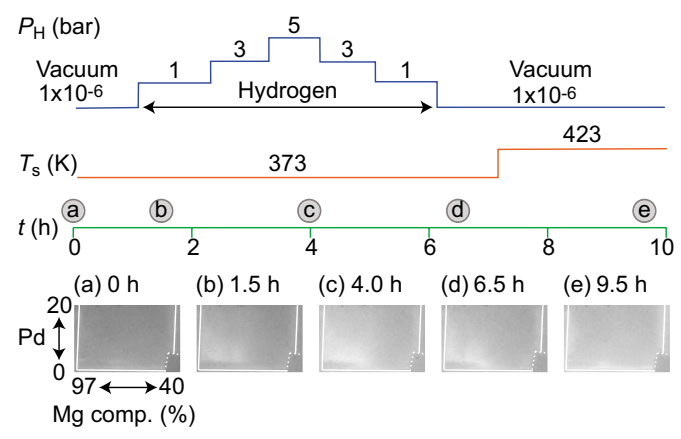

FIG. 5. (Color online) The measurement schedule [hydrogen gas pressure $\left(P_{\mathrm{H}}\right)$, sample temperature $\left(T_{\mathrm{S}}\right)$, and time $\left.(t)\right]$ and five representative top view IR images of the $\mathrm{Mg}-\mathrm{Ni}$ composition spread sample at (a) $0 \mathrm{~h}$, (b) $1.5 \mathrm{~h}$, (c) $4.0 \mathrm{~h}$, (d) $6.5 \mathrm{~h}$, and (e) $9.5 \mathrm{~h}$. Initially the sample was stabilized at $373 \mathrm{~K}$ in vacuum for $1 \mathrm{~h}$, after which $P_{\mathrm{H}}$ was increased to 1,3 , and 5 bar every hour. Subsequently $P_{\mathrm{H}}$ was decreased using the same schedule down to vacuum. Finally, $T_{s}$ was increased to $423 \mathrm{~K}$. The image acquisition time is shown on the top of each image and is marked by circle on the time line. The position of the thin film sample and the clamp are outlined by the solid and dashed white lines, respectively. Mg composition and Pd thickness gradient are shown in (a). 


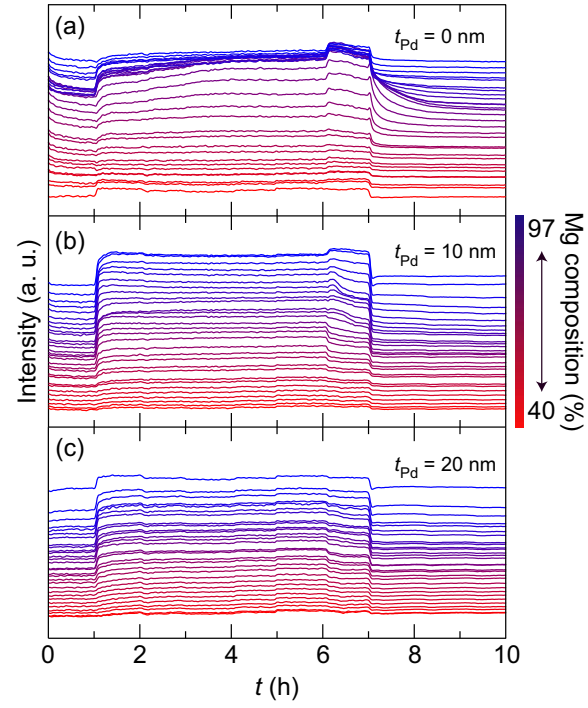

FIG. 6. (Color online) 30 IR intensity curves of measurement spots along the $\mathrm{Mg}-\mathrm{Ni}$ composition spread for three different thickness of the Pd capping layer $\left(t_{\mathrm{Pd}}\right) \cdot t_{\mathrm{Pd}}$ (a) $0 \mathrm{~nm}$, (b) $10 \mathrm{~nm}$, and (c) $20 \mathrm{~nm}$, respectively. A Si substrate was used as an inert reference for normalization. The composition of each curve is represented by the curve color as illustrated by the color bar on the right-hand side. The curves are offset vertically for clarity, with the more $\mathrm{Mg}$ results placed at the upper side of the figure.

(left) of the sample increases brightness. The increase in brightness is more obvious in the region with the thinner $\mathrm{Pd}$ capping layer (bottom), which is consistent with our previous study of the effect of thickness of the Pd capping layer on the IR imaging. Apparently, transformation of Pd to Pd hydride during the experiment does not affect the IR-blocking behavior of the Pd capping layer, probably because of the metallic character of Pd hydride. ${ }^{51}$ As $P_{\mathrm{H}}$ increases, both the magnitude and the spatial range of the brightness increase due to further hydrogenation of the sample [Fig. 5(c)]. In contrast, as $P_{\mathrm{H}}$ decreases, both the magnitude and the spatial range of the brightness decrease due to partial dehydrogenation of the sample [Fig. 5(d)]. Finally at $T_{s}=423 \mathrm{~K}$, brightness disappeared maybe due to complete dehydrogenation [Fig. 5(e)]. As illustrated here, looking at the IR images enables us to grasp the hydrogenation and dehydrogenation feature of a thin film sample with locally varied parameters immediately.

However, there are some features we cannot understand by simply looking at the IR images. Thus the IR images were analyzed and IR intensity curves are plotted in Figs. 6(a)-6(c). Regardless of $\mathrm{Mg}-\mathrm{Ni}$ composition and $t_{\mathrm{Pd}}$, there are rapid hydrogenation at $t=1 \mathrm{~h}$ and rapid dehydrogenation at $t=7 \mathrm{~h}$ indicated by rapid intensity increase and decrease, respectively. In addition, slight dehydrogenation is indicated by a small intensity decrease between $t=6$ and $7 \mathrm{~h}$, where $P_{\mathrm{H}}=1 \times 10^{-6}$ bar and $T_{s}=373 \mathrm{~K}$ (see schedule in Fig. 5). The remarkable difference among different $t_{\mathrm{Pd}} s$ is that, only for $t_{\mathrm{Pd}}=0 \mathrm{~nm}$, rapid intensity changes are followed by slow intensity changes indicating slow hydrogenation or dehydrogenation for composition range of $51 \leq \mathrm{Mg}$ composition $(\%) \leq 77$.

Borgschulte et al. ${ }^{52}$ previously reported that the kinetics of hydrogenation of the yttrium thin film increases for thicker Pd capping layers. Their result may help explain the slow increase and decrease in IR intensity observed here for $t_{\mathrm{Pd}}=0 \mathrm{~nm}$. Another possible reason is potential oxidization of the thin film surface. Although $\mathrm{Mg}$ is very sensitive to oxidization, ${ }^{53}$ our sample was transferred in ambient atmosphere from the deposition chamber to the reaction chamber. Thus, the surface with a very thin (and can be discontinuous) Pd capping layer is likely to be partially or fully oxidized. The oxidization would be more severe and suppresses hydrogenation and dehydrogenation in the region with the higher $\mathrm{Mg}$ composition. This may explain smaller increase and decrease in IR intensity for $t_{\mathrm{Pd}}=0 \mathrm{~nm}$ [Fig. 6(a)] than for $t_{\mathrm{Pd}}$ $=10 \mathrm{~nm}$ [Fig. 6(b)] and $20 \mathrm{~nm}$ [Fig. 6(c)] with a composition range between $80 \leq \mathrm{Mg}$ composition $(\%) \leq 97$.

In Figs. 6(b) and 6(c), the magnitude of the IR intensity change increases almost linearly with $\mathrm{Mg}$ composition in accordance with the increase in hydrogen storage capacity, ${ }^{54}$ which suggests the semiquantitative capability of the IR imaging to hydrogen storage capacity. One limitation of the IR imaging is its limited signal-to-noise ratio even after normalization discussed in this report. For example, discontinuous intensity changes occur in Figs. 6(a)-6(c) at $t \approx 6 \mathrm{~h}$ when $P_{\mathrm{H}}$ was pumped down to $1 \times 10^{-6}$ bar. The reason for this discontinuity can be insufficient heating or cooling of the chamber by introduction and mixing of hydrogen gas. Unfortunately, it is difficult to separate the noise from the meaningful intensity change due to hydrogenation and dehydrogenation. In order to discern meaningful information from noise, however, one can plot all the IR intensity curves obtained under the same experimental conditions together using the combinatorial approach. Then systematic intensity changes with the systematically varied physical parameters, e.g., composition, can be delineated.

\section{Detection of formation of a $\mathrm{Mg}_{2} \mathrm{Si}$ phase}

Here we demonstrate capability of the IR imaging to detect formation of new phases by monitoring a Mg thickness gradient thin film sample [Fig. 7(a)] annealed at $573 \mathrm{~K}$ in vacuum. Representative top view IR images [Figs. $7(b)-7(d)]$ show that during the course of annealing, the bright region emerges from the thinner $\mathrm{Mg}$ side (left) and propagates toward the thicker $\mathrm{Mg}$ side (right). To study details of the behavior of the IR intensity change, IR intensity curves with continuously varied $\mathrm{Mg}$ thickness are plotted in Fig. 7(e). A pronounced increase in IR intensity is observed for each curve but it gradually delays with increasing thickness of the $\mathrm{Mg}$ thin film. As annealing was implemented in vacuum, the origin of the increase in intensity cannot be attributed to reaction of the $\mathrm{Mg}$ thin film with residual gases but rather to some structural changes affecting the intrinsic IR emissivity.

The most plausible explanation for this observation is the interdiffusion of different components of the heterogeneous sample and potential formation of new phases; either $\mathrm{Pd}$ diffusion from the capping layer or Si diffusion from the substrate into the $\mathrm{Mg}$ thin film, or both. If the change originates from $\mathrm{Mg}-\mathrm{Pd}$ phase formation due to the $\mathrm{Pd}$ diffusion, the diffusion is expected to occur uniformly from the surface and thus the increase in intensity would have been observed simultaneously for each thickness of $\mathrm{Mg}$. This disagrees with 

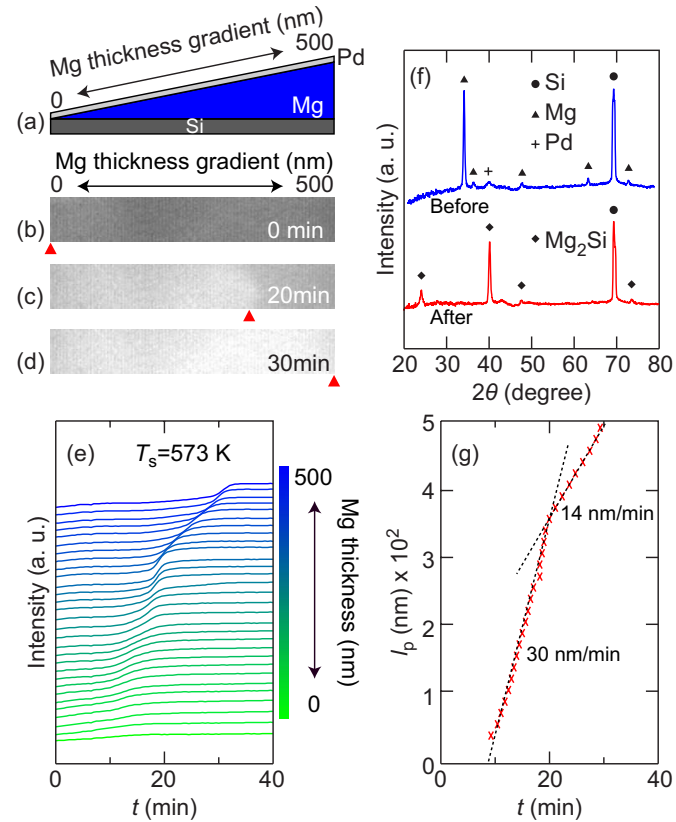

FIG. 7. (Color online) (a) A cross-sectional schematic of a Mg thickness gradient thin film sample with a $5 \mathrm{~nm}$ thick Pd capping layer deposited on a thermally oxidized $\mathrm{Si}(100)$ substrate. Representative top view IR images of the $\mathrm{Mg}$ thickness gradient thin film sample annealed for (b) 0 min, (c) 20 min, and (d) $30 \mathrm{~min}$ at $573 \mathrm{~K}$, respectively. A red triangle denotes position of the boundary line between the dark region and bright region. (e) 30 IR intensity curves of measurement spots along the Mg thickness gradient. A Si substrate was used as an inert reference for normalization. The Mg thickness of the IR intensity curves are represented by the curve color as illustrated by the color bar on right-hand side, and offset vertically for clarity with the thicker Mg results placed at the upper side of the figure. (f) Representative $\theta-2 \theta$ XRD patterns of $500 \mathrm{~nm}$ thick $\mathrm{Mg}$ before (blue) and after (red) annealing. The diffraction peaks of the $\mathrm{Pd}$ and the $\mathrm{Mg}_{2} \mathrm{Si}$ at around $40.3^{\circ}$ overlapped and are hard to distinguish. (g) Propagation length $\left(l_{p}\right)$ of the $\mathrm{Mg}_{2} \mathrm{Ni}$ phase formation front as a function of time $(t)$.

our observation. On the other hand, if the origin is $\mathrm{Mg}-\mathrm{Si}$ phase formation due to $\mathrm{Si}$ diffusion into the $\mathrm{Mg}$ thin film, the diffusion would have occurred from the bottom of the $\mathrm{Mg}$ thin film, and the increase in intensity would have not been observed until a newly formed $\mathrm{Mg}-\mathrm{Si}$ phase reached the thin film surface. In this case, the increase in intensity associated with formation of the $\mathrm{Mg}-\mathrm{Ni}$ phase should be delayed for thicker Mg. Thus the observation supports Si diffusion.

In order to verify formation of the $\mathrm{Mg}-\mathrm{Si}$ phase, the $\mathrm{Mg}$ thickness gradient thin film sample was investigated using XRD before and after annealing. The XRD patterns [Fig. 7(f)] show diffraction peaks originating from $\mathrm{Mg}, \mathrm{Pd}$, and $\mathrm{Si}$ before annealing (blue) and from $\mathrm{Mg}_{2} \mathrm{Si}$ and $\mathrm{Si}$ after annealing (red). This is supportive evidence that significant diffusion of Si has occurred during annealing yielding the formation of a $\mathrm{Mg}_{2} \mathrm{Si}$ phase. As the $\mathrm{Mg}_{2} \mathrm{Si}$ phase is a $n$-type semiconductor, the change in the electric characteristic of the thin film from metallic to semiconducting may results in increase in IR emissivity. ${ }^{55,56}$

Provided that the formation front of the $\mathrm{Mg}_{2} \mathrm{Si}$ phase propagates from a substrate toward a thin film surface, the increase in IR intensity begins at the moment the front reached the thin film surface after propagating the distance equals to the thickness of the $\mathrm{Mg}$ thin film. The speed of propagation of the $\mathrm{Mg}_{2} \mathrm{Si}$ phase formation front is deter- mined from the plot of propagation length $l_{\mathrm{p}}$ (=thickness of the Mg thin film) as a function of $t$ at which increase in IR intensity begins [Fig. 7(g)]. Apparently there are two slopes in Fig. 7(g); the formation front of the $\mathrm{Mg}_{2} \mathrm{Si}$ phase initially propagates fast, and then slows down. From the slopes of the straight lines on which data points fit, the speed of propagation of the $\mathrm{Mg}_{2} \mathrm{Si}$ phase formation front was determined as 30 and $14 \mathrm{~nm} / \mathrm{min}$ for fast and slow propagation, respectively. The slowdown may be explained by the formation of the $\mathrm{Mg}_{2} \mathrm{Si}$ continuous layer on the $\mathrm{Si}$ substrate, in which $\mathrm{Si}$ diffusion might be hindered. Details of the propagation mechanism are under investigation.

\section{CONCLUSION}

We have developed an IR imaging setup enabling in situ IR images to be acquired and expanded on capabilities of an IR imaging as a high-throughput screening technique. The critical thickness of the Pd capping layer, which significantly blocks IR emission from below was experimentally determined to be $\approx 30 \mathrm{~nm}$. Normalization of raw IR image data to an inert reference such as a substrate enhances sensitivity to hydrogenation and dehydrogenation. The IR imaging of a $\mathrm{Mg}$ thin film in hydrogenation and dehydrogenation process confirmed that an increase and decrease in IR intensity are attributed to hydrogenation and dehydrogenation, respectively. The IR imaging of a $\mathrm{Mg}-\mathrm{Ni}$ composition spread sample with a thickness gradient Pd capping layer revealed that the amount of absorbed hydrogen changes systematically with composition, and the kinetics changes with the thickness of the Pd capping layer. Finally we have demonstrated an interesting capability of the IR imaging, i.e., detection of phase formation and determination of its propagation speed, by detecting formation of the $\mathrm{Mg}_{2} \mathrm{Si}$ phase in the $\mathrm{Mg}$ thin film on the Si substrate during annealing.

\section{ACKNOWLEDGMENTS}

We wish to thank Dr. Larry Cook of the NIST Ceramics Division for his help and participation in designing and building the chamber, temperature controller, and gas handling system. We are also grateful to Dr. Makoto Otani of the NIST Ceramics Division for his help to develop analysis programs.

${ }^{1}$ DOE 2007 Annual Merit Review Proceedings Hydrogen Storage, http://www.hydrogen.energy.gov/annual_review07_storage.html.

${ }^{2}$ L. Schlapbach and A. Züttel, Nature (London) 414, 353 (2001).

${ }^{3}$ L. Schlapbach, I. Anderson, and J. P. Burger, in Electronic and Magnetic Properties of Metals and Ceramics Part III, edited by K. H. J. Buschow (VCH, Weinheim, 1994), Vol. 3B, p. 271.

${ }^{4} \mathrm{DOE}$ Targets for on-board hydrogen storage systems, http://www1.eere.energy.gov/hydrogenandfuelcells/storage/ current_technology.html.

${ }^{5}$ A. Züttel, P. Wenger, S. Rentsch, P. Sudan, Ph. Mauron, and Ch. Emmenegger, J. Power Sources 118, 1 (2003).

${ }^{6}$ Y. Nakamori and S. Orimo, J. Alloys Compd. 370, 271 (2004).

${ }^{7}$ T. Kohno, H. Yoshida, F. Kawashima, T. Inaba, I. Sakai, M. Yamamoto, and M. Kanda, J. Alloys Compd. 311, L5 (2000).

${ }^{8}$ B. Bogdanović and M. Schwickardi, J. Alloys Compd. 253-254, 1 (1997). ${ }^{9}$ M. Hirscher, M. Becher, M. Haluska, U. Dettlaff-Weglikowska, A. Quintel, G. S. Duesberg, Y. M. Choi, P. Downes, M. Hulman, S. Roth, I. Stepanek, and P. Bernier, Appl. Phys. A: Mater. Sci. Process. 72, 129 (2001). 
${ }^{10}$ T. Yildirim and S. Ciraci, Phys. Rev. Lett. 94, 175501 (2005).

${ }^{11}$ S. Orimo and H. Fujii, Appl. Phys. A: Mater. Sci. Process. 72, 167 (2001).

${ }^{12}$ R. Schulz, J. Huot, G. Liang, S. Boily, G. Lalande, M. C. Denis, and J. P. Dodelet, Mater. Sci. Eng., A 267, 240 (1999).

${ }^{13}$ L. Zaluski, A. Zaluska, and J. O. Ström-Olsen, J. Alloys Compd. 253, 70 (1997).

${ }^{14}$ C. Suryanarayana and C. C. Koch, Hyperfine Interact. 130, 5 (2000).

${ }^{15}$ N. Cui, P. He, and J. L. Luo, Acta Mater. 47, 3737 (1999).

${ }^{16}$ J. Huot, G. Liang, and R. Schulz, Appl. Phys. A: Mater. Sci. Process. 72, 187 (2001).

${ }^{17}$ H. Chang, I. Takeuchi, and X.-D. Xiang, Appl. Phys. Lett. 74, 1165 (1999).

${ }^{18}$ I. Takeuchi, H. Chang, C. Gao, P. G. Schultz, X.-D. Xiang, R. P. Sharma, M. J. Downers, and T. Venkatesan, Appl. Phys. Lett. 73, 894 (1998).

${ }^{19}$ J. Wang, Y. Too, C. Gao, I. Takeuchi, X. Sun, H. Chang, X.-D. Xiang, and P. G. Schultz, Science 279, 1712 (1998).

${ }^{20}$ H. Chang, C. Gao, I. Takeuchi, Y. Yoo, J. Wang, P. G. Schultz, X.-D. Xiang, R. P. Sharma, M. Downes, and T. Venkatesan, Appl. Phys. Lett. 72, 2185 (1998).

${ }^{21}$ I. Takeuchi, O. O. Famodu, J. C. Read, M. A. Aronova, K.-S. Chang, C. Craciunescu, S. E. Lofland, M. Wuttig, F. C. Wellstood, L. Knauss, and A. Orozco, Nature Mater. 2, 180 (2003).

${ }^{22}$ D. A. R. Barkhouse, A. Bonakdarpour, M. Fleischauer, T. D. Hatchard, and J. R. Dahn, J. Magn. Magn. Mater. 261, 399 (2003).

${ }^{23}$ M. Yu, H. Oguchi, A. J. Zambano, I. Takeuchi, J. P. Liu, D. Josell, and L. A. Bendersky, Mater. Sci. Eng., B 142, 139 (2007).

${ }^{24}$ A. Ludwig, J. Cao, A. Savan, and M. Ehmann, J. Alloys Compd. 446, 516 (2007).

${ }^{25}$ S. Guerin, B. E. Hayden, and D. C. A. Smith, J. Comb. Chem. 10, 37 (2008).

${ }^{26}$ R. Gremaud, C. P. Broedersz, D. M. Borsa, A. Borgschulte, P. Mauron, H. Schreuders, J. H. Rector, B. Dam, and R. Griessen, Adv. Mater. (Weinheim, Ger.) 19, 2813 (2007).

${ }^{27}$ B. Dam, R. Gremaud, C. Broedersz, and R. Griessen, Scr. Mater. 56, 853 (2007).

${ }^{28}$ C. H. Olk, G. G. Tibbetts, D. Simon, and J. J. Moleski, J. Appl. Phys. 94, 720 (2003)

${ }^{29}$ L. D. Landau and E. M. Lifshitz, Statistical Physics, 3rd ed. (Pergamon, New York, 1980).

${ }^{30}$ N. F. Mott and H. Jones, The Theory of the Properties of Metals and Alloys (Dover, Oxford, 1936).

${ }^{31}$ A. V. Sokolov, Optical Properties of Metals (Elsevier, New York, 1967).

${ }^{32}$ L. D. Landau and E. M. Lifshitz, Electrodynamics of Continuous Media (Pergamon, New York, 1960).
${ }^{33}$ F. Cuevas, J. F. Fernandez, and C. Sanchez, J. Alloys Compd. 253, 158 (1997).

${ }^{34}$ A. W. Szafrański, Phys. Status Solidi A 175, 665 (1999).

${ }^{35}$ A. K. M. Fazle Kibria, Int. J. Hydrogen Energy 25, 997 (2000).

${ }^{36}$ D. E. Azofeifa and N. Clark, J. Alloys Compd. 305, 32 (2000).

${ }^{37}$ H. E. Bennett and J. O. Porteus, J. Opt. Soc. Am. 51, 123 (1961).

${ }^{38}$ We confirmed the microscopically smooth surface using transmission electron microscopy.

${ }^{39}$ K. Higuchi, K. Yamamoto, H. Kajioka, K. Tomiyama, M. Honda, S. Orimo, and H. Fujii, J. Alloys Compd. 330-332, 526 (2002).

${ }^{40}$ M. Zhu, H. Wang, L. Z. Ouyang, and M. Q. Zeng, Int. J. Hydrogen Energy 31, 251 (2006).

${ }^{41}$ M. Johansson, C. W. Ostenfeld, and I. Chorkendorff, Phys. Rev. B 74, 193408 (2006).

${ }^{42}$ C. W. Ostenfeld, J. C. Davies, T. Vegge, and I. Chorkendorff, Surf. Sci. 584, 17 (2005).

${ }^{43}$ Y. Pivak, R. Gremaud, K. Gross, M. Gonzalez-Silveira, A. Walton, D. Book, H. Shreuders, B. Dam, and R. Griessen, Scr. Mater. 60, 348 (2009).

${ }^{44}$ R. Gremaud, M. Gonzalez-Silveira, Y. Pivak, S. de Man, M. Slaman, H. Shreuders, B. Dam, and R. Griessen, Acta Mater. 57, 1209 (2009).

${ }^{45}$ Certain commercial equipment, instruments, or materials are identified in this document. Such identification does not imply recommendation or endorsement by the National Institute of Standards and Technology, nor does it imply that the products identified are necessarily the best available for the purpose.

${ }^{46}$ I. Takeuchi, M. Lippmaa, and Y. Matsumoto, MRS Bull. 31, 999 (2006).

${ }^{47}$ H. Koinuma and I. Takeuchi, Nature Mater. 3, 429 (2004).

${ }^{48}$ M. G. Cattania, V. Penka, R. J. Behm, K. Christmann, and G. Ertl, Surf. Sci. 126, 382 (1983).

${ }^{49}$ Ch. Resch, H. F. Berger, K. D. Rendulic, and E. Bertel, Surf. Sci. 316, L1105 (1994).

${ }^{50}$ R. A. H. Niessen and P. H. L. Notten, J. Alloys Compd. 404, 457 (2005).

${ }^{51}$ P. A. Bennett and J. C. Fuggle, Phys. Rev. B 26, 6030 (1982).

${ }^{52}$ A. Borgschulte, W. Lohstroh, R. J. Westerwaal, H. Schreuders, J. H. Rector, B. Dam, and R. Griessen, J. Alloys Compd. 404, 699 (2005).

${ }^{53}$ P. Lin, H. Zhou, W. Li, W. Li, N. Sun, and R. Yang, Corros. Sci. 50, 2669 (2008).

${ }^{54}$ R. L. Holtz and M. A. Imam, J. Mater. Sci. 32, 2267 (1997).

${ }^{55}$ T. S. Kamilov, D. K. Kabilov, R. Kh. Kamilova, M. E. Azimov, V. V. Klechkovskaya, A. S. Orekhov, and E. I. Suvorova, Proceedings of the International Conference on Thermoelectrics, 2006 (unpublished), p. 468.

${ }^{56}$ N. G. Galkin, S. V. Vavanova, A. M. Maslov, and K. N. Galkin, Proc. SPIE 5129, 313 (2003). 